\title{
A EFICÁCIA DAS MEDIDAS DE CONTROLE PARA A MITIGAÇÃO DE RISCOS NO PROCESSO DE PAGAMENTO DE PESSOAL CIVIL NO COMANDO DA AERONAUTICA
}

\author{
SALES, Sheyla ${ }^{1}$ \\ ARAÚJO, Richard Medeiros de ${ }^{2}$ \\ BRANDÃO, Pamela de Medeiros ${ }^{3}$
}

Recebido em: 2017.12 .20

Aprovado em: 2018.04.17

ISSUE DOI: $10.3738 / 1982.2278 .2915$

\begin{abstract}
RESUMO: Esse artigo analisa a eficácia das medidas de controle adotadas pelo Comando da Aeronáutica para a mitigação de riscos de dano ao Erário no processo de pagamento de pessoal civil. Para tanto identificou os riscos inerentes ao pagamento do pessoal civil, oriundos dos acórdãos do TCU emitidos no período de 2006 a 2015 contra o Comando da Aeronáutica; e verificaram-se as medidas de controle adotadas pelo Comando da Aeronáutica para eliminar ou mitigar os riscos encontrados. Trata-se de uma pesquisa descritiva com abordagem qualitativa, que adotou como técnica de coleta de dados a pesquisa documental e a entrevistas com representantes dos três órgãos principais do Comando da Aeronáutica envolvidos com o processo de pagamento de pessoal: Subdiretoria de Pagamento de Pessoal (SDPP), Diretoria de Administração de Pessoal (DIRAP) e Subdiretoria de Inativos e Pensionistas (SDIP). Dentre os principais resultados, tem-se que a avaliação de risco de pagamento de pessoal civil, destacam-se: não pagamento proporcional das gratificações da pensão civil, desvio de recursos de pensionistas falecidos, pensão civil ilegal a menor sob guarda, inobservância da paridade dos benefícios na pensão civil com a remuneração do cargo efetivo do falecido, reajustes pagos indevidamente, averbação ilegal de tempo de serviço, pensão civil ilegal a filho maior ocupante de cargo público e acúmulo ilegal de proventos/pensões ou cargos públicos. Por fim, avalia-se que o processo de pagamento de pessoal do Comando da Aeronáutica é eficaz na medida em que tem sido adotadas medidas de controle que possibilitam a detecção dos riscos encontrados nos acórdãos do TCU no período investigado.
\end{abstract}

Palavras-chave: Risco. Eficácia. Pagamento de pessoal.

SUMMARY: This article analyzes the effectiveness of the control measures adopted by the Aeronauti Command to mitigate the risks of damage to the ereasury in the process of payment of civilian personnel. To this end, it identified the risks inherent to the payment of civilian personnel, resulting from the TCU judgments issued in the period from 2006 to 2015 against the Aeronautical Command; And verified the control measures adopted by the Aeronautics Command to eliminate or mitigate the risks encountered. This is a descriptive research with a qualitative approach, which used as a data collection technique the documentary research and interviews with representatives of the three main organs of the Aeronautics Command involved with the personnel payment process: Personnel Payroll Subdirectorate (SDPP), the Personnel Management Board (DIRAP) and the Inactive and Pensioners Subdirectorate (SDIP). Among the main results, the risk assessment of civilian personnel is as follows: non-proportional payment of civil pension benefits, misappropriation of funds from deceased pensioners, illegal civilian pension under guardianship, non-observance of parity Of the benefits in the civil pension with the remuneration of the effective position of the deceased, improperly paid readjustments, illegal record of time of service, illegal civil pension to the child occupying more public office and illegal accumulation of pensions or public positions. Finally, it is evaluated that the process of payment of personnel of the Command of the Aeronautics is effective to the extent that have been adopted control measures that allow the detection of the risks found in the judgments of the TCU in the period investigated.

Keywords: Risk. Efficiency. Payment of personnel.

\footnotetext{
${ }^{1}$ Mestre em Gestão publica pelo PPGP UFRN

2 Doutor em Administração pelo PPGA/UFRN

${ }^{3}$ Doutora em Administração pela UFBA e profa do PPGP/UFRN
} 


\section{INTRODUÇÃO}

No Brasil, especialmente a partir da década de 1990, sob influência de um projeto político neoliberal, inicia-se a uma série de reformas do Estado no âmbito administrativo com o intuito de aumentar a qualidade das ações governamentais, sendo a adoção do paradigma gerencial concebido como um caminho para, entre outros aspectos, garantir melhores resultados em termos de eficácia, qualidade do serviço e no ganho dos beneficiários. (KEATING, 2001, p.145). Essas reformas buscavam introduzir a utilização de sistemas de gerenciamento de performance, maior responsabilização e accountability para os gestores públicos, maior competição no setor público e introdução de práticas de gerenciamento da qualidade (MAESSCHALCK, 2004), tais como a descentralização, delegação de autoridade e controle sobre o desempenho, com forte ênfase na eficácia do serviço público (GIACOMO, 2005).

Além disso, ao adotar medidas administrativas orientadas para a obtenção de resultado e para o controle de gastos públicos, a reforma do Estado permitiria auxiliar no combate à corrupção. A melhora da ação governamental a partir dos controles processuais tornou-se uma das promessas da chamada Nova Gestão Pública, conforme ressaltam Sano e Abrúcio (2008). Para alcançar esse objetivo, o Estado intensificou, por exemplo, a adoção de medidas de controle no processo de pagamento de pessoal civil no âmbito da administração pública com vistas a detectar e corrigir inconsistências e indícios de irregularidades.

Nesse direcionamento, as auditorias realizadas por órgãos de controle externo do governo federal se apresentam como um procedimento de fiscalização e monitoramento do gasto público brasileiro. Para tanto, o Tribunal de Contas da União (TCU) possui competências estabelecidas pela Constituição Federal de 1988 para, dentre outras, apreciar a legalidade do processo de pagamento de pessoal civil e militar. De tal modo que a análise das auditorias realizadas pelo Tribunal de Contas da União (TCU) permite refletir sobre a eficácia do processo de pagamento de pessoal do Comando da Aeronáutica na mitigação dos riscos apurados.

Assim sendo, esse artigo checa a eficácia das medidas de controle adotadas pelo Comando da Aeronáutica para a mitigação de riscos de dano ao Erário no processo de pagamento de pessoal civil, ou seja, evitar os erros administrativos, humanos e processuais que gerem despesas equivocadas para o Estado. Nesse direcionamento, realizou-se um levantamento dos riscos inerentes ao pagamento do pessoal civil, oriundos dos acórdãos do TCU emitidos no período de 2006 a 2015 contra o Comando da Aeronáutica; e verificaram-se as medidas de controle adotadas pelo Comando da Aeronáutica para eliminar ou mitigar os riscos encontrados.

Para sistematizar os resultados da pesquisa, esse artigo divide-se em cinco sessões, sendo a primeira composta por essas considerações iniciais, seguindo-se da fundamentação teórica sobre eficácia e avaliação de risco. Na terceira sessão, descrevem-se os procedimentos metodológicos adotados, e na quarta apresentam a análise e discussão dos dados. Por fim, terce-se na quinta sessão as considerações finais e apresentam-se recomendações para melhorias do processo de pagamento de pessoal civil do COMAER.

\section{FUNDAMENTAÇÃO TEÓRICO-EMPÍRICA}

\subsection{EFICÁCIA}

Esta pesquisa baseou-se no conceito de Eficácia para compreensão do processo de pagamento de pessoal. Grateron (1999) entende que a eficácia de uma entidade ou gestor público é medida pelo grau de 
cumprimento dos objetivos e metas fixados nos programas de ação. Esta medida é feita através da comparação entre os resultados realmente obtidos e os resultados esperados ou previstos nos planos ou programas de ação, independentemente da quantidade, qualidade e custo dos recursos envolvidos em atingir estes objetivos.

Ainda segundo Grateron (1999), para poder avaliar a eficácia é necessária a existência de um planejamento por programas em que as metas e objetivos estejam claramente identificados e, na medida do possível, quantificados, descrevendo-se as atividades necessárias para atingi-los. A avaliação da eficácia estabelece a relação não só entre os resultados obtidos e os planejados, previstos ou esperados, senão também com o resultado ótimo. Eficácia, conforme Reis e Machado Jr (1994, p. 318), diz respeito ao atingimento de objetivos e metas organizacionais.

Figueredo e Figueredo (1986) tratam o termo eficácia como avaliação de metas. Em geral é feita pelos próprios órgãos encarregados da execução da política. Enquadram-se aqui os relatórios anuais das entidades e as estatísticas que estes produzem com o intuito de demonstrar que "cumpriram com as expectativas", no que se refere ao volume e à qualidade de produto. O critério de sucesso para este autor é o da eficácia objetiva, isto é, se as metas atingidas são iguais, superiores ou inferiores às metas propostas.

De acordo com Gonzalez et al. (2011), pode-se definir eficácia como sendo a capacidade de alcançar as metas e os objetivos almejados e planejados com base nos recursos disponíveis em determinado tempo. Trata-se também da capacidade de atender aos propósitos e metas no tempo, lugar, qualidade e quantidade certa. Rego e Cunha (2006) salientam que a eficácia possui seu próprio princípio, qual seja, para se alcançar um resultado, a organização terá que exigir a menor quantidade de eventos possíveis. As discrepâncias e desacordos deverão ser eliminados e apenas serão produzidos eventos encadeados integral e organicamente direcionados para os resultados desejados. Desta forma, nota-se que, segundo os autores, a eficácia trata-se, do grau em que se executam as tarefas planejadas e se alcançam os resultados desejados.

Assim, Glória (2013) defende que a eficácia está relacionada diretamente ao que fazer e como fazer, com base em uma decisão correta a se seguir. Nesse contexto, eficácia refere-se à escolha correta do que e como fazer para que os resultados sejam alcançados de modo produtivo. A eficácia é determinada por Rego e Cunha (2006), como o grau em que os resultados esperados atendam às necessidades do ambiente externo, ou seja, aos clientes. Para Carvalho (2007), eficácia significa desempenho, performance, rentabilidade e rendimento. Eficácia também representa sobrevivência ou viabilidade, igualando a sucesso, criatividade, excelência e qualidade, ou ainda, força da experiência afetiva.

Os teóricos em ciências organizacionais consideram, frequentemente, que é impossível descrever a eficácia das organizações de maneira simples uma vez que a interpretação escolhida dependeria da teoria organizacional e dos interesses específicos nos quais se inspiram aqueles que põem a questão da eficácia (CAMERON, WHETTEN, 1983; FAERMAN, QUINN, 1985). Além disso, a eficácia organizacional tem se mostrado como sendo um dos maiores objetivos da gestão atual, já que trata da capacidade que a organização possui de alcançar seus propósitos estabelecidos. Carvalho (2007) afirma que a eficácia organizacional possibilita uma produção de alta qualidade e de maior facilidade de adaptação às mudanças ocorridas no ambiente externo, sem diminuir a satisfação dos clientes.

Freitas (2010) afirma que o conceito de eficácia passou a ser considerado como a capacidade de estruturar atividades em volta dos fatores ambientais. Os indicadores de eficácia eram considerados com base no nível de adaptação que a organização tinha em seu meio e a comparação dos resultados alcançados com os que foram propostos pela organização. A importância que se tinha em considerar a eficácia com base na avaliação dos indicadores de ordem econômico-financeira, tais como, a qualidade 
humana que a organização tinha e a sua adaptação ao meio. Tal avaliação exigia o levantamento de dados sobre o consumo referente aos esforços, energia, dinheiro, mão-de-obra qualificada, dentre outros.

As instituições públicas também passaram a dirigir suas ações na busca pela eficácia. Fernandes e Ribeiro (2009) afirmam que a eficácia organizacional refere-se a um fenômeno não apenas complexo, mas também multidimensional que está relacionado diretamente com a teoria e prática da eficácia governamental. Nesse sentido, os autores citando Quin e Rohrbaugh $(1981 ; 1983)$ apresentam quatro dimensões de eficácia para as organizações, quais sejam: a dimensão das relações humanas, a dimensão do sistema aberto, a dimensão dos objetivos racionais e a dimensão dos processos internos.

Além dessas dimensões, Fernandes (2006) acrescenta a existência da dimensão política na eficácia, a qual se encontra dispersa pelos diversos quadrantes do modelo. Essas dimensões, conforme Fernandes (2006), não são igualmente exclusivas para todas as organizações, podendo haver, ou não, no processo produtivo e na busca pela eficácia organizacional, a utilização de algumas ou nenhuma delas. Sendo, também, verdade que a maior parte das organizações possui propriedades de mais de uma das cinco culturas de cada dimensão de eficácia organizacional.

Abordando-se as referidas dimensões de eficácia, Fernandes e Ribeiro (2009) afirmam que na dimensão das relações humanas, a participação, as discussões abertas, o trabalho em equipe, a coesão, as ideias dos colaboradores e o moral são os elementos principais. Já a dimensão do sistema aberto é caracterizada pelo novo, pela mudança e criatividade para se resolver problemas, incluindo a descentralização e a abertura a ideias inovadoras. Igualmente, Quinn e Rohrbaugh (1981 e 1983) tratam o paradigma racional da eficácia como aquele que a organização enfatiza os valores da cultura hierárquica e de grupo para que os fins sejam alcançados. Por isso, a avaliação da eficácia organizacional depende não só de critérios de eficácia econômica, mas também de critérios de eficácia social.

No que concerne à dimensão dos processos internos ou econômica, Quinn e Rohrbaugh (1981 e 1983) e Savoie e Morin (2001) salientam que nessa abordagem se busca a otimização econômica porque é graças ao valor acrescentado que se torna possível a obtenção e manutenção das contribuições necessárias à consecução dos objetivos de equilíbrio financeiro e crescimento. Quanto à dimensão do poder e da política, Robbins (1990) e Bilhim (1996) esclarecem que essa dimensão possui algumas características da dimensão do sistema aberto, no entanto, acrescenta-se a questão da estrutura baseada no poder. Para os autores acima referenciados, em muitos casos por haver ausência de racionalidade entre os membros da organização há necessidade de os conflitos de interesses serem respondidos através do exercício do poder provenientes de coligações políticas que determinam os critérios que deverão prevalecer. Observa-se que esta dimensão está relacionada ao poder relativo de cada um dos grupos de interesses, ou seja, pelas diferentes dimensões de eficácia organizacional.

Segundo Fernandes (2006), de modo geral, ao se falar em eficácia organizacional, remete-se à intenção de solucionar os problemas no contexto dos negócios da organização. Devido a isso, o autor acredita que os critérios que determinam a eficácia estão fundamentados e derivados qualidade do serviço. Ele explica que a compreensão da dinâmica das organizações no que se refere à eficácia não está baseada apenas na busca de explicação e previsão dos seus resultados, mas, inclusive, no entendimento dos fatores que as condicionam a alcançar melhores resultados do que outras. É desta forma que, verificando-se os fatores que levam ao sucesso, a organização poderá promover a eficácia organizacional.

\subsection{Avaliação de risco e a metodologia IFAC}

Os riscos de controle interno e a atividade de compliance estão diretamente ligados ao tema desta pesquisa. Segundo Padoveze e Bertolucci (2013, p. 326), estes riscos são inúmeros e vão desde o 
desempenho inadequado das tarefas à possibilidade de fraudes, até a existência de processos e fluxos de trabalho mal estruturados, sem os conceitos e as condições mínimas necessárias para um grau de confiança esperado.

Brito (2003) exemplifica riscos de controle interno como sendo falhas ou faltas de controle, avaliação errada, software inadequado ou modelo matemático inadequado. Para Braga (2013), risco é uma discussão sistêmica e deve ser analisada diante de três dimensões temporais. Olhando o passado, deve-se observar se esse fato compõe um elenco de fatos similares, que podem gerar uma tendência comum, indicando um modelo que pode nos ajudar a entender as forças sistêmicas que levaram àquela ocorrência.

Braga (2013) entende que a lógica de riscos dos controles internos permite olhar uma situação encontrada na auditoria não pela sua tipicidade ou aspecto incomum e sim, como reflexo de uma falha sistêmica, que merece não somente soluções pontuais, mas também reformulações de sua estrutura com a finalidade de prevenir a ocorrência de situações similares no futuro. O TCU (2003, p.3) define risco como a expressão da probabilidade de ocorrência e do impacto de eventos futuros e incertos que têm potencial para influenciar o alcance dos objetivos de uma organização, e como a suscetibilidade de ocorrência de eventos que afetem negativamente a realização dos objetivos das unidades jurisdicionadas (TCU, 2008, p.2). Essas conceituações trazem embutida a noção de que, para se ter conhecimento dos riscos de uma organização, deve-se primeiro conhecer seus objetivos.

A avaliação do risco, enquanto um componente basilar do controle interno, objetiva redução da probabilidade de eventos negativos sem incorrer em custos excessivos ou paralisação da organização. Por isso, trata-se de um procedimento necessária para acompanhamento do nível de risco aceitável ou definição do limite máximo aceitável por uma organização.

Para a avaliação e priorização dos riscos existem diversas metodologias de avaliação, dentre as quais se destacam as metodologias de Robillard (2001), Avalos (2009), COCO, Fama, Cardoso e Mendonça (2002), a da Análise dos Modos de Falha e Seus Efeitos (Failure Mode and Effect Analysis FMEA) e a International Federation of Accountants (IFAC), sendo esta última a adotada como modelo para esta pesquisa, por permitir verificar a ocorrência absoluta dos riscos baseada na observação de eventos ocorridos no passado.

O International Federation of Accountants possui uma visão mais corporativa dos riscos, entendendo-os como "eventos futuros incertos que podem influenciar o atendimento dos objetivos estratégicos, operacionais e financeiros da organização." Segundo essa metodologia "as dimensões do risco incluem o impacto sobre a reputação de uma organização, incluindo a perda de legitimidade devida a atividades consideradas inaceitáveis para a comunidade". (IFAC, 1999, p. 6)

Para a IFAC (2001), o gerenciamento de risco é definido como um processo para: a) entender os objetivos organizacionais; b) identificar os riscos associados ao alcance desses objetivos, em uma base contínua, de forma a poder reagir a (ou iniciar) mudanças de uma maneira apropriada e oportuna; c) estimar os riscos, em termos da probabilidade de algo acontecer e o seu potencial impacto; d) estabelecer políticas apropriadas e procedimentos para gerenciá-las, na proporção dos riscos ou oportunidades envolvidos; e) monitorar e avaliar os riscos e os programas ou procedimentos utilizados para tratá-los. Revisar riscos passados e buscar se antecipar aos futuros e monitorar mudanças nos ambientes interno e externo para obter informação que possa sinalizar uma necessidade de se reavaliar os objetivos da entidade ou do controle.

A Metodologia IFAC (1999) consiste em avaliar impacto e probabilidade de ocorrência. Para tanto, propõe que os riscos enfrentados por uma organização podem ser de duas naturezas distintas: riscos de conformance (que será traduzido por conformidade) e riscos de performance (que será traduzido por desempenho). De acordo com essa metodologia, os riscos assumem três sentidos distintos: perigo ou 
ameaça, incerteza e oportunidade; e a avaliação do impacto desses riscos deve considerar: a gama de resultados possíveis, o risco de ocorrência várias vezes no mesmo intervalo de tempo, o impacto financeiro, o impacto na viabilidade e nos objetivos da organização e o impacto político e na comunidade. Para Padoveze e Bertolucci (2013, p. 217): os impactos dos riscos podem ser classificados em três níveis:

a) ALTO: O impacto financeiro na organização poderia exceder, por exemplo, $\$ z$ milhões, ou haveria impacto significativo na viabilidade da organização ou em seus objetivos estratégicos/operacionais, ou poderia haver impacto político ou comunitário significativo.

b) MÉDIO: O impacto financeiro na organização estaria entre \$y milhões e \$z milhões, ou haveria impacto moderado na viabilidade da organização ou em seus objetivos estratégicos/operacionais, ou poderia haver impacto moderado político ou comunitário.

c) BAIXO: O impacto financeiro na organização estaria entre \$x milhões e \$y milhões, ou haveria impacto mínimo na viabilidade da organização ou em seus objetivos estratégicos/operacionais, ou poderia haver mínimo impacto político ou comunitário. (PADOVEZE, BERTOLUCCI, 2013, p. 217)

A avaliação da probabilidade de ocorrência, segundo IFAC (1999), possui três visões diferentes, dentre elas: a) Avaliação bruta: reflete a probabilidade inerente de ocorrência do evento na ausência de quaisquer processos que a organização possa ter para reduzi-la; b) Avaliação líquida: avalia a probabilidade levando em conta as condições reais e os processos para redução da possibilidade de ocorrência do evento;e c)Avaliação meta: reflete o apetite que a organização tem pelo risco.

Steinberg et al. (2003, p. 47) coaduna com o mesmo pensamento do IFAC ao apontar que: "A gerência considera tanto o risco inerente quanto o residual. Risco inerente é aquele em que se incorre na ausência de quaisquer ações que a gerência possa tomar para alterar probabilidade ou impacto/risco residual é o que permanente após a resposta gerencial ao risco". Após definição do tipo de avaliação a se adotar, Padoveze e Bertolucci (2013) sugerem a adoção de escala de critérios de avaliação probabilidade de ocorrência a qual foi adaptada do $\operatorname{IFAC}(1999$, p. 19) e varia entre alta, média e moderada e provável, possível e remota, conforme sistematiza-se no Quadro 1:

Quadro 1 - Avaliação da probabilidade de ocorrência

\begin{tabular}{|c|c|c|}
\hline AVALIAÇÃO & DESCRIÇÃO & INDICADORES \\
\hline Alta & $\begin{array}{l}\text { Provável } \\
\text { Possibilidade de ocorrer, uma média } \\
\text { igual ou maior a uma vez por ano, em } \\
\text { um período de dez anos ou a chance de } \\
\text { acontecer acima de } 100 \%\end{array}$ & $\begin{array}{l}\text { Potencial para ocorrer várias vezes nos } \\
\text { próximos dez anos. } \\
\text { Número de ocorrências nos últimos dez anos } \\
\text { \% de ocorrência nos últimos dez anos. } \\
\text { Típico em operações dessa natureza devido a } \\
\text { influências externas. }\end{array}$ \\
\hline Mod & $\begin{array}{l}\text { Possível } \\
\text { Possibilidade de ocorrer, em um } \\
\text { período de dez anos, } 2 \text { a } 4 \text { casos ou a } \\
\text { chance de acontecer maior que } 20 \% \text { e } \\
\text { menor que } 40 \%\end{array}$ & $\begin{array}{l}\text { Poderia ocorrer mais de uma vez nos } \\
\text { próximos dez anos. } \\
\text { Pode ser de difícil controle devido a algumas } \\
\text { influências externas. } \\
\text { Número de ocorrências nos últimos dez anos } \\
\% \text { de ocorrência nos últimos dez anos. } \\
\text { Existe histórico de ocorrência na organização. }\end{array}$ \\
\hline Baixa & $\begin{array}{l}\text { Remota } \\
\text { Improvável de ocorrer num período de } \\
\text { dez anos,ocorreu apenas um caso no } \\
\text { período de dez anos ou a chance de } \\
\text { acontecer menor do que } 20 \%\end{array}$ & $\begin{array}{l}\text { Número de ocorrências nos últimos dez anos. } \\
\% \text { de ocorrência nos últimos dez anos. } \\
\text { Uma ocorrência seria surpreendente. }\end{array}$ \\
\hline
\end{tabular}

Fonte: Adaptado de IFAC (1999, p.19) 
O quadro 1 reforça o entendimento da gradação da probabilidade de ocorrência, de forma qualitativa, cujos percentuais e períodos foram sugeridos pela autora desta pesquisa em razão de conveniência e observação da ocorrência absoluta dos riscos detectados no passado. Em seguida, o IFAC (1999) sugere a utilização da ferramenta chamada mapa do risco ou matriz do risco a qual combina as duas dimensões avaliadas e classifica os riscos conforme Figura 1.

Figura 1 - Modelo de matriz de risco

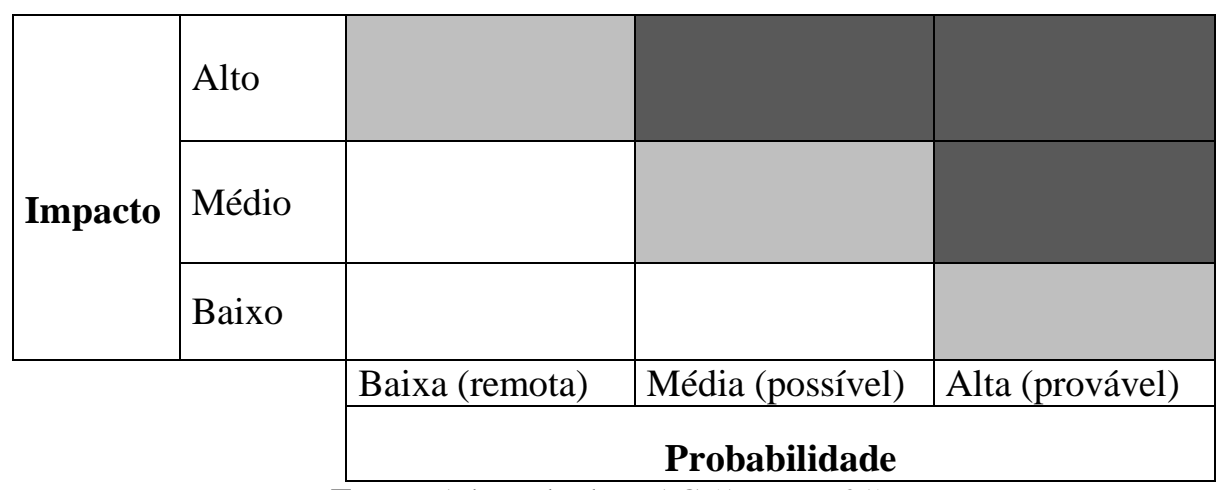

Fonte: Adaptado de IFAC (1999, p. 21).

A figura 1 representa uma resposta gerencial ao risco. A organização, diante da análise da figura, deve priorizar adoção de medidas de redução de riscos quanto aos itens das células em cinza escuro e, em seguida, os itens das células em cinza médio porque estes representam os riscos de maior probabilidade de ocorrência e de maior impacto. Após avaliação dos riscos, cabe o levantamento das possíveis respostas para mitigação dos mesmos. Segundo IFAC (1999, p.37), o componente final para um gerenciamento de risco eficaz é uma estrutura de relatório e monitoramento para assegurar que as lacunas na resposta ao risco sejam preenchidas e que as suas respostas continuem a operar eficazmente e permaneçam apropriadas à luz de condições mutáveis.

\section{METODOLOGIA}

A presente pesquisa, de acordo com as taxonomias apresentadas por Gil (2009), caracteriza-se como descritiva, por objetivar mapear as características dos procedimentos adotados no processo de pagamento de pessoal do Comando da Aeronáutica, os erros e fraudes mais comuns que motivaram instauração de Tomada de Contas Especial nesta área ou simplesmente emissão de acórdão pelo TCU. Adotou-se uma abordagem qualitativa, uma vez que a avaliação de risco do processo de pagamento foi realizada de acordo com a Metodologia IFAC (1999) a qual consiste em avaliar os riscos qualitativamente quanto ao impacto e à probabilidade de ocorrência.

Adotou-se como técnica de coleta de dados a entrevista e a pesquisa documental. As entrevistas foram realizadas numa amostragem por conveniência (OLIVEIRA, 2003) com representantes dos três principais órgãos do COMAER envolvidos com o processo de pagamento de pessoal, quais sejam: Subdiretoria de Pagamento de Pessoal (SDPP), Diretoria de Administração de Pessoal (DIRAP) e Subdiretoria de Inativos e Pensionistas (SDIP), todos sediados no Rio de Janeiro. Totalizando uma amostra de 10 entrevistados que estão associados diretamente ao objeto de estudo, em face de suas atividades cotidianas e o objetivo da pesquisa, sendo: 01 representante da Tesouraria País da SDPP (pp4), que realiza contato direto entre as entidades bancárias conveniadas; 01 representante do Sistema Informatizado de Pagamento de Pessoal da SDPP (pp6), e 01 responsável pelo setor de processamento do 
sistema informatizado; 02 conferente de Pagamento de Pessoal da SDPP (pp3-1 e pp3-2), responsáveis diretos pela conferência dos lançamentos da folha de pagamento de pessoal e da homologação da folha de pagamento de pessoal civil; e 03 representante da DIRAP, responsável pela conferência dos processos de habilitação de pensão civil, responsável pelo lançamento dos dados de títulos de inativos e pensionistas civis no Sistema de Controle de Ações de Comunicação (SISAC) e o responsável pela conferência da averbação de tempo de serviço para efeito de aposentadoria.

Utilizou-se como instrumentos de coletas de dados um roteiro de entrevistas semiestruturado, cujas perguntas buscaram compreender: 1) procedimentos adotados no processo de pagamento de pessoal do Comando da Aeronáutica; 2) objetivos do processo de pagamento de pessoal do Comando da Aeronáutica; 3) fraudes, riscos e eficácia; 4) avaliação da eficácia das medidas de controle adotadas pelo Comando da Aeronáutica; 5) avaliação dos riscos. Para os dados coletados desse instrumento aplicou-se a análise de conteúdo, em conformidade com a técnica proposta por Bardin (2006). Essas etapas foram organizadas em três fases: 1) pré-análise, 2) exploração do material e 3) tratamento dos resultados, inferência e interpretação. Após transcrição das entrevistas, leituras dos documentos, e compreensão da relação conceitual com os dados, estruturou-se as categorias da análise no estudo.

E na pesquisa documental analisou-se documentos relativos a COMAER, tais como Instrução do Comando da Aeronáutica (ICA) 177-36/2009, MCA 177-2, Regulamento de Administração da Aeronáutica ou Regulamento do Comando da Aeronáutica RCA n 12-1/2014 (RADA) e acórdãos do TCU emitidos nos últimos dez anos (período de 2006 a 2015) atinentes a pagamento de pessoal no Comando da Aeronáutica.

Foram analisados todos os 92 acórdãos emitidos pelo TCU no período de 2006 a 2015 acerca de pagamento de pessoal do Comando da Aeronáutica, por meio da análise documental. Para cada acórdão verificou-se os procedimentos adotados no processo de cotejamento de pagamento de pessoal do Órgão e demais medidas de controle adotadas pela Subdiretoria de Pagamento de Pessoal (SDPP), Diretoria de Pessoal da Aeronáutica (DIRAP) e Subdiretoria de Inativos e Pensionistas (SDIP).

Esse procedimento permitiu elaborar quadros que evidenciaram os procedimentos adotados no processo de pagamento de pessoal, bem como os riscos detectados pelo TCU, no âmbito do COMAER, no período de 2006 a 2015, para facilitar a identificação e correlação dos dados coletados. Após levantamento dos riscos constantes dos acórdãos e legislação sobre cotejamento de pagamento de pessoal, procedeu-se a pré-análise da avaliação do risco, selecionando os dados por tipo de fraude/risco, por tipo de pagamento civil ou militar, valor do dano ao Erário, número de ocorrência do mesmo tipo de fraude/erro, organizando-os por valor de impacto e por probabilidade de ocorrência. Posteriormente a esta fase, elaborou-se a matriz de risco.

Para avaliação da eficácia, foi necessária a pré-análise dos riscos encontrados nos acórdãos e das medidas de controle adotadas pelos Órgãos envolvidos com o processo de pagamento de pessoal do Comando da Aeronáutica, organizando-os em forma de quadro para facilitar a visualização e análise dos dados coletados. Ao final, a análise dos dados propiciou o enquadramento do processo ora estudado em um dos dois critérios de eficácia: a) eficaz: se o processo possibilitar a detecção de todos os tipos de erros ou fraudes encontrados nos acórdãos do TCU (objetivo da auditoria para este trabalho); e b) ineficaz: se o processo impossibilitar a detecção dos erros ou fraudes encontrados nos acórdãos do TCU. Os critérios escolhidos para definição do conceito de eficácia, neste trabalho, levaram em consideração que o alto grau de risco de incorrer em dano ao Erário gera consequências graves para a Administração, sendo necessária a implementação de medidas que reduzam a ocorrência de desvios na área de pagamento de pessoal.

Quanto ao impacto, foi adotada a escala constante do Quadro 2 como forma de avaliação do impacto dos riscos: 
Quadro 2 - Critérios de avaliação do impacto dos riscos

\begin{tabular}{|c|l|}
\hline $\begin{array}{c}\text { ESCALA DO } \\
\text { IMPACTO }\end{array}$ & $\begin{array}{l}\text { CONCEITO } \\
\text { valor mínimo para abertura de Tomada de Contas Especial ou impacto significativo na } \\
\text { viabilidade da organização ou em seus objetivos estratégicos/operacionais, ou } \\
\text { poderia haver impacto político ou comunitário significativo. }\end{array}$ \\
\hline MÉDIO & $\begin{array}{l}\text { O impacto financeiro na organização inferior a } \mathrm{R} \$ 75.000,00 \text { (setenta e cinco mil reais) } \\
\text { e superior a } \mathrm{R} \$ 1.000,00 \text { (hum mil reais), valor mínimo para inscrição na Dívida Ativa } \\
\text { da União, ou haveria impacto moderado na viabilidade da organização ou em seus } \\
\text { objetivos estratégicos/operacionais, ou poderia haver impacto moderado político } \\
\text { ou comunitário. }\end{array}$ \\
\hline BAIXO & $\begin{array}{l}\text { O impacto financeiro na organização inferior a } \mathrm{R} \$ 1.000,00 \text { (hum mil reais), valor } \\
\text { mínimo para inscrição na Dívida Ativa da União, ou haveria impacto mínimo na } \\
\text { viabilidade da organização ou em seus objetivos estratégicos/operacionais, ou } \\
\text { poderia haver mínimo impacto político ou comunitário. }\end{array}$ \\
\hline
\end{tabular}

Fonte: Adaptado de Padoveze e Bertolucci ( 2013, p. 217)

Foram considerados de alto impacto aqueles riscos que ultrapassaram o valor mínimo estipulado pelo Tribunal de Contas da União para abertura de processo Tomada de Contas Especial, prevista no inciso I do art. $6^{\circ}$ da Instrução Normativa TCU n ${ }^{\circ} 71$, de 28 de novembro de 2012, ou seja, quantia mínima de R $\$ 75.000,00$ (setenta e cinco mil reais). Para isso, levou-se em consideração que a abertura deste tipo de processo além de desgastar a imagem do Órgão, indica a fragilidade do sistema na ocorrência dos riscos em razão da ocorrência de fraudes e de dano ao Erário, demandando-se medidas de controle urgentes. Como baixo impacto, foram considerados os riscos inferiores a $\mathrm{R} \$ 1.000,00$ (hum mil reais), haja vista ser o limite mínimo para inscrição na Dívida Ativa da União conforme previsto no inciso I do art. $1^{\circ}$ da Portaria $\mathrm{n}^{\circ} 75$, de 22 de março de 2012, emitida pelo Ministério da Fazenda. O impacto médio consiste nos valores compreendidos no intervalo de $\mathrm{R} \$ 1.000,00$ (hum mil reais) e $\mathrm{R} \$ 75.000,00$ (setenta e cinco mil reais), haja vista a possibilidade de inscrição na Dívida Ativa da União, execuções fiscais de débitos com a Fazenda Nacional superiores a R \$1.000,00 (hum mil reais), conforme previsto no inciso I do art. $1^{\circ}$ da Portaria ${ }^{\circ} 75$, de 22 de março de 2012, do Ministério da Fazenda.

Quanto à probabilidade de ocorrência, adotou-se a escala adaptada de IFAC (1999) (ver Quadro 1), mediante a observação da ocorrência absoluta dos riscos detectados no passado. Considesou-se visão líquida que, segundo IFAC (1999), consiste em avaliar a probabilidade levando em conta as condições reais e os processos para redução da possibilidade de ocorrência do evento. Para tanto, foi adotado o parâmetro de amostragem de acordo com o número ou percentual de ocorrência no período de dez anos, comprendnedo três possibilidades: (1) Caso a média de ocorrência de erros/fraudes seja maior ou igual a uma por ano, ou seja, igual ou maior que 100\%, a probabilidade será considerada Alta; (2) Caso o número de ocorrência de erros/fraudes, no período de dez anos, seja maior que 2 e menor que 4, ou seja, maior que $20 \%$ e menor que 40\%, a probabilidade será considerada Moderada; (3) Caso o número de ocorrência de erros/fraudes, no período de dez anos, seja menor que 2, ou seja, seja menor que $20 \%$, a probabilidade será considerada Baixa. 


\section{ANÁLISE E DISCUSSÃO DOS DADOS}

\subsection{Estudo do risco do processo de pagamento de pessoal civil}

Inicialmente, quanto ao estudo do risco do pagamento do pessoal civil, após análise dos 92 acórdãos do TCU, emitidos no período de 2006 a 2015, envolvendo o Comando da Aeronáutica, constatou-se a existência de 74 acórdãos acerca de pagamento de pessoal civil. Destes, excluindo-se os com motivos repetidos, reduzem para 14 os motivos que originaram acórdãos do TCU. Em seguida, buscou-se classificar os referidos riscos ora encontrados da maior para a menor probabilidade seguindo escala de critérios de avaliação de probabilidade de ocorrência proposta por Padoveze e Bertolucci (2013) e adaptada pela metodologia IFAC (1999).

Ressalta-se também que na análise dos acórdãos de pagamento de pessoal civil não foi possível a quantificação do impacto uma vez que os acórdãos emitidos não discriminavam o valor do dano em razão da aplicação da súmula 106 do TCU a qual dispensa a devolução das quantias indevidamente recebidas de boa-fé pelos servidores. Durante a entrevista com representante de pagamento civil da SDPP, obteve-se a informação de que: "Estes tipos de processos perfazem um valor médio de $\mathrm{R} \$ 30.000,00$ (trinta mil reais) por pessoa e por ano (Representante de pagamento civil da SDPP)."

Ademais, constatou-se que os acórdãos do TCU não foram emitidos em decorrência de abertura de tomada de contas especial o que descaracteriza a existência de dano ao Erário superior a R \$75.000,00 (setenta e cinco mil reais). Constatou-se também, durante a entrevista junto a representante da DIRAP SISAC, que a emissão de Acórdão pelo TCU acerca de análise de títulos de pensão é uma tarefa rotineira do Órgão, senão vejamos trecho da entrevista: "O TCU possui a incumbência de analisar todos os títulos de pensão civil e militar emitidos pelo Comando da Aeronáutica à medida que são elaborados. Os dados são enviados pelo CENCIAR por meio do sistema do TCU chamado de SISAC (Sistema de Controle de Ações de Comunicação)" (Representante da DIRAP - SISAC).

Em razão disso, padronizou-se o impacto de todos os acórdãos de pagamento de pessoal civil como médio, ou seja, acima de $\mathrm{R} \$ 1.000,00$ (hum mil reais) e inferior a $\mathrm{R} \$ 75.000,00$ (setenta e cinco mil reais). A Quadro 3 representa o resumo dos acórdãos de pagamento civil do COMAER.

Quadro 3 - Resumo dos Acórdãos de Pagamento Civil do Comaer, no período de 2006 a 2015

(Continua)

\begin{tabular}{|l|c|c|c|}
\hline \multicolumn{1}{|c|}{ MOTIVO RESUMIDO } & Ocorrência & $\begin{array}{c}\text { Probabili } \\
\text { em 10 anos } \\
\text { dade de } \\
\text { ocorrênci } \\
\text { a }\end{array}$ & $\begin{array}{c}\text { Média } \\
\text { valor do } \\
\text { impacto } \\
\text { para cada } \\
\text { caso }\end{array}$ \\
\hline $\begin{array}{l}\text { Não pagamento proporcional das gratificações da pensão } \\
\text { civil }\end{array}$ & 115 & alta & médio \\
\hline Desvio de recursos de pensionistas falecidos & 91 & alta & médio \\
\hline Pensão civil ilegal a menor sob guarda & 28 & alta & médio \\
\hline $\begin{array}{l}\text { Inobservância da paridade dos benefícios na pensão civil } \\
\text { com a remuneração do cargo efetivo do falecido. }\end{array}$ & 27 & alta & médio \\
\hline Reajustes pagos indevidamente & 23 & alta & médio \\
\hline Averbação ilegal de tempo de serviço & 17 & alta & médio \\
\hline
\end{tabular}


Quadro 3 - Resumo dos Acórdãos de Pagamento Civil do Comaer, no período de 2006 a 2015

(Conclusão)

\begin{tabular}{|l|c|c|c|}
\hline \multicolumn{1}{|c|}{ MOTIVO RESUMIDO } & Ocorrência & $\begin{array}{c}\text { Probabili } \\
\text { dade de } \mathbf{1 0} \text { anos } \\
\text { ocorrênci } \\
\text { a }\end{array}$ & $\begin{array}{c}\text { Média } \\
\text { valor do } \\
\text { impacto } \\
\text { para cada } \\
\text { caso }\end{array}$ \\
\hline $\begin{array}{l}\text { Pensão civil ilegal a filho maior ocupante de cargo } \\
\text { público }\end{array}$ & 17 & alta & médio \\
\hline Acúmulo ilegal de proventos/pensões ou cargos públicos & 12 & alta & médio \\
\hline Pensão civil ilegal à pessoa designada & 10 & alta & médio \\
\hline Pagamento de gratificação/vantagem/adicional indevido & 9 & alta & médio \\
\hline Pensão civil ilegal a filho inválido, sem comprovação & 9 & alta & médio \\
\hline $\begin{array}{l}\text { Não aplicação do redutor de pensão civil prevista no } \\
\text { inciso i do art. 2 }{ }^{\circ} \text { da lei 10.887/2004 e ec 41/2003 }\end{array}$ & 5 & alta & médio \\
\hline Aposentadoria por invalidez, sem comprovação & 3 & moderada & médio \\
\hline Habilitação ilegal de pensão à concubina & 3 & moderada & médio \\
\hline
\end{tabular}

Fonte: Elaboração própria (2016)

Os dados do Quadro 3 resume a classificação dos acórdãos de pagamento de pessoal civil do Comando da Aeronáutica, no período de 2006 a 2015, ordenando-os da maior para a menor probabilidade de ocorrência. Neste sentido, destaca-se, como o risco de maior probabilidade, não pagamento proporcional das gratificações da pensão civil, liderando a tabela com 115 casos ocorridos nos dez anos investigados

Retomando-se os parâmetros utilizados para tratamento dos dados nesta pesquisa, são considerados riscos de alta probabilidade de ocorrência aqueles com possibilidade de ocorrer em uma média igual ou maior a uma vez por ano, em um período de dez anos. Desta forma, enquadram-se como riscos de alta probabilidade de ocorrência: Não pagamento proporcional das gratificações da pensão civil, desvio de recursos de pensionistas falecidos, pensão civil ilegal a menor sob guarda, inobservância da paridade dos benefícios na pensão civil com a remuneração do cargo efetivo do falecido, reajustes pagos indevidamente, averbação ilegal de tempo de serviço, pensão civil ilegal a filho maior ocupante de cargo público, acúmulo ilegal de proventos/pensões ou cargos públicos, pensão civil à pessoa designada, pagamento de gratificação/vantagem adicional indevido, pensão civil ilegal a filho inválido, sem comprovação e não aplicação do redutor de pensão civil previsto no inciso I do art. $2^{\circ}$ da lei $\mathrm{n}^{\circ}$ 10.887/2004 E EC 41/2003.

São considerados riscos de moderada probabilidade de ocorrência aqueles com possibilidade de ocorrer 2 a 4 casos, em um período de dez anos. Desta forma, enquadram-se como riscos de moderada probabilidade de ocorrência: a aposentadoria por invalidez, sem comprovação e habilitação ilegal de pensão à concubina. São considerados riscos de baixa probabilidade de ocorrência aqueles com possibilidade de ocorrer apenas um caso no período de dez anos. Desta forma, constata-se que não houve risco de baixa probabilidade de ocorrência. A figura 2 representa a matriz de risco elaborada acerca de pagamento de pessoal civil do Comando da Aeronáutica. 
Figura 2-Matriz de Risco de Pagamento Civil do COMAER, no período de 2006 a 2015.

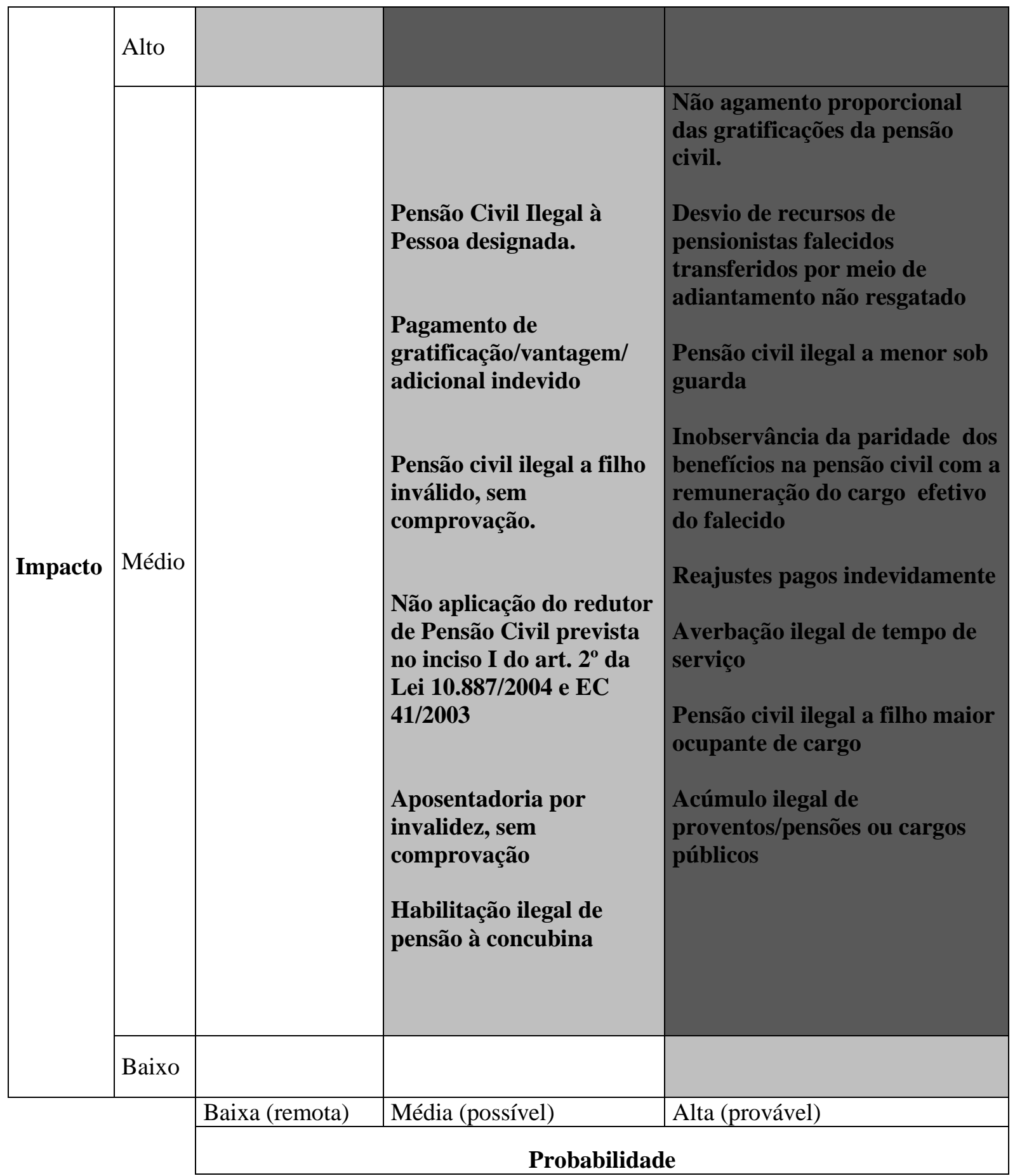

Fonte: Elaboração própria (2016)

A análise do impacto e da probabilidade do risco do pagamento de pessoal civil propiciou a elaboração de uma matriz de risco, conforme figura 2, a qual demonstra que o Comando da Aeronáutica deve priorizar a mitigação principalmente dos riscos constantes da faixa cinza escuro, cuja probabilidade e impacto enquadram-se nos maiores patamares, quais sejam: Não pagamento proporcional das gratificações da pensão civil, desvio de recursos de pensionistas falecidos, pensão civil ilegal a menor sob guarda, inobservância da paridade dos benefícios na pensão civil com a remuneração do cargo efetivo do falecido, reajustes pagos indevidamente, averbação ilegal de tempo de serviço, pensão civil ilegal a filho maior ocupante de cargo público e acúmulo ilegal de proventos/pensões ou cargos públicos. 
Em seguida, o Comando da Aeronáutica deverá priorizar a mitigação dos riscos constantes da faixa cinza claro, cuja probabilidade e impacto enquadram-se nos patamares médios, quais sejam: pensão civil à pessoa designada, pagamento de gratificação/vantagem adicional indevido, pensão civil ilegal a filho inválido, sem comprovação, não aplicação do redutor de pensão civil previsto na EC 41/2003 e no inciso I do art. $2^{\circ}$ da lei $\mathrm{n}^{\circ} 10.887 / 2004$, aposentadoria por invalidez, sem comprovação e habilitação ilegal de pensão à concubina (BRASIL, 2003;2004). Por último, não houve riscos enquadrados na faixa branca que são os que se enquadram nos patamares mais baixos de probabilidade e impacto.

\subsection{Estudo da eficácia do processo de pagamento de pessoal civil}

O estudo da eficácia do pagamento de pessoal civil do Comando da Aeronáutica baseou-se no conceito definido por Reis e Machado Jr (1994, p. 318): "eficácia diz respeito ao atingimento de objetivos e metas. Sua preocupação é com resultados. Se uma organização tem claramente definidos os seus objetivos e estes são atingidos, dizemos que a organização é eficaz". Portanto, buscou-se checar se o objetivo da Instituição foi alcançado no processo de pagamento de pessoal: executar e controlar o pagamento de pessoal no país e no exterior com excelência. Como anteriormente já mencionado, tal objetivo foi extraído da missão, visão e valores da Subdiretoria de Pagamento de Pessoal (SDPP) conforme definidos em seu sítio eletrônico: www.sdpp.aer.mil.br.

Após o conhecimento dos riscos inerentes ao pagamento do pessoal civil, oriundos dos acórdãos do TCU emitidos, no período de 2006 a 2015, buscou-se apurar, por meio das entrevistas e da análise documental, se o Comando da Aeronáutica vem adotando medidas de controle para eliminar ou mitigar os riscos encontrados.

Para mitigar o risco de não pagamento proporcional das gratificações da pensão civil, constatouse que o processo passa pela conferência da OM, da DIRAP, da SDIP e do Centro de Controle Interno da Aeronáutica (CENCIAR). Além disso, anualmente, a DIRAP ministra instrução, convocando todos os gestores de pessoal civil do COMAER, para orientar e elucidar dúvidas nos procedimentos a serem adotados no exercício de suas funções.

Essa mesma medida tem sido adotada quanto aos riscos de inobservância da paridade dos benefícios na pensão civil com a remuneração do cargo efetivo do falecido, de reajustes pagos indevidamente, de pagamento de gratificação/vantagem/adicional indevido e de não aplicação do redutor de pensão civil prevista na EC 41/2003 e no inciso I do art. $2^{\circ}$ da lei 10.887/2004 (BRASIL, 2003; 2004).

Portanto, diante das ferrramentas de controle utilizadas quanto aos riscos de não pagamento proporcional das gratificações da pensão civil, de inobservância da paridade dos benefícios na pensão civil com a remuneração do cargo efetivo do falecido, de reajustes pagos indevidamente, de pagamento de gratificação/vantagem/adicional indevido e de não aplicação do redutor de pensão civil prevista na EC 41/2003 (conferência do processo pela OM, DIRAP, SDIP e CENCIAR e instrução anual junto aos gestores de pessoal civil do COMAER), constata-se que existe segurança na mitigação destes riscos, uma vez que os controles preventivos adotados reduzem a possibilidade de ocorrência das falhas inerentes ao processo, identificando-se os possíveis erros e causas de possíveis falhas e atendendo à análise ideal de eficácia, segundo Dias (2008).

Quanto ao risco de desvio de recursos de pensionistas falecidos, transferidos por meio de adiantamento não resgatado, este risco foi eliminado com o cancelamento da rubrica de adiantamento de pessoal civil e reduzido por meio do cruzamento dos óbitos no SISOBI, conforme relato do entrevistado representante de pessoal civil da SDPP-PP3: 
A rubrica de adiantamento de pagamento a pessoal civil foi cancelada, com isso, este risco foi eliminado. Além disso, há conferência mensal da prestação de contas de pagamento por folha extraordinária pela SDPP e há o cruzamento mensal dos pagamentos de pessoal civil com o Sistema de Óbitos (SISOBI), cabendo ao responsável pelo cadastro da OM atualizar os dados no Sistema SIAPE, reduzindo-se, assim, o risco de pagamento de funcionários fantasmas (Representante da SDPP-PP3).

Portanto, conjugando-se as três ferrramentas de controle do risco de desvio de recursos de pensionistas falecidos, transferidos por meio de adiantamento não resgatado (impossibilidade de adiantamento de pagamento à pensionista civil ou civil, conferência da prestação de contas mensal de folha extraordinária pela SDPP e cruzamento de dados de óbito do SISOBI com o SIAPE/SIGEPE), constata-se que existe segurança na mitigação destes riscos, uma vez que eliminam ou minimizam as falhas inerentes ao processo, identificando-se os possíveis erros e causas de possíveis falhas e atendendo à análise ideal de eficácia, segundo Dias (2008).

Quanto ao risco de pensão civil ilegal a menor sob guarda, com a edição da Lei $\mathrm{n}^{\circ}$ 8.112, de 11 de dezembro de 1990, por meio da Lei $\mathrm{n}^{\circ} 13.135$, de 17 de junho de 2015 , foi revogada a possibilidade de habilitação de menor sob guarda à pensão civil. A mesma medida de controle foi adotada quanto ao risco de pensão civil ilegal à pessoa designada haja vista que com a edição dessas referidas leis também revogaram a possibilidade de habilitação de pessoa designada à pensão civil.

Portanto, diante da ferrramenta de controle utilizada quanto aos riscos de pensão civil ilegal a menor sob guarda e de pensão civil ilegal à pessoa designada (criação da Lei $\mathrm{n}^{\circ}$ 13.135, de 17 de junho de 2015, que revogou a possibilidade de habilitação de ambas hipóteses à pensão civil), constata-se que existe segurança na eliminação destes riscos, uma vez que os controles preventivos adotados eliminam as falhas inerentes ao processo, identificando-se os possíveis erros e causas de possíveis falhas e atendendo à análise ideal de eficácia, segundo Dias (2008).

Quanto ao risco de averbação ilegal de tempo de serviço observou-se, pelo depoimento do entrevistado representante da DIRAP - AVERBAÇÃO DE TEMPO DE SERVIÇO, que passou a realizar diligência junto aos Órgãos que apresentam a declaração de tempo de serviço, conforme relato abaixo:

Atualmente, este risco de averbação ilegal de tempo de serviço foi minimizado em decorrência das diligências que são realizadas junto aos Órgãos públicos que emitem a declaração de tempo de serviço anterior ao civil no COMAER para averbação e contagem do tempo para aposentadoria e junto ao INSS, quando o civil apresenta tempo de serviço na iniciativa privada. Tal procedimento inibe a emissão de declaração falsa principalmente pelas Prefeituras e ou pelas empresas da iniciativa privada (Representante da DIRAP - AVERBAÇÃO DE TEMPO DE SERVIÇO).

Diante do exposto, constata-se que a ferramenta de controle ora adotada pela DIRAP quanto ao risco de averbação ilegal de tempo de serviço (diligência junto aos Órgãos públicos que emitem a declaração de tempo de serviço e ao INSS, quando o tempo de serviço averbado refere-se à iniciativa privada), proporciona segurança na mitigação do risco, uma vez que o controle preventivo adotado elimina as falhas inerentes ao processo, identificando-se os possíveis erros e causas de possíveis falhas e atendendo à análise ideal de eficácia, segundo Dias (2008).

Quanto aos riscos de pensão civil ilegal o filho maior ocupante de cargo público e de acúmulo ilegal de proventos/pensões ou cargos públicos, este é minimizado por meio da existência das trilhas de auditoria do TCU, conforme afirma o representante da SDPP-PP3-2:

O TCU cruza mensalmente os dados da folha de pagamento de pessoal civil da Aeronáutica com a de outros Órgãos públicos com a finalidade de verificar nas trilhas de 
auditoria a existência de acúmulo ilegal de cargos públicos, pensões ou proventos. Cabe ao gestor de finanças ou de pessoal e agente de controle interno das organizações militares registrarem as providências adotadas no acompanhamento destas trilhas diretamente no sítio eletrônico do TCU. Os Órgãos centrais como DIRAP, SDPP e SDIP também acompanham o andamento destas trilhas de auditoria do TCU (Representante da SDPP-PP3-2).

Portanto, apura-se que a ferramenta de controle adotada para os riscos de pensão civil ilegal a filho maior ocupante de cargo público e de acúmulo ilegal de proventos/pensões ou cargos públicos (trilhas de auditoria do TCU) proporciona segurança na mitigação destes riscos, elimina as falhas inerentes ao processo, identificando-se os possíveis erros e causas de possíveis falhas e atendendo à análise ideal de eficácia, segundo Dias (2008). Quanto ao risco de pensão civil ilegal à filho inválido, sem comprovação e quanto ao risco de aposentadoria por invalidez, sem comprovação, o representante da DIRAP - CIVIL entrevistado informou que: "Nestes casos, é exigido laudo médico atual homologado pela Junta Regular de Saúde do Comando da Aeronáutica que comprove a invalidez (Representante da DIRAP-CIVIL)".

A ICA 47-3/2003, que trata da habilitação de pensão civil, exige no item 7.2 a comprovação de invalidez do beneficiário de pensão, mediante inspeção de saúde por Junta Regular de Saúde do Comando da Aeronáutica, conforme abaixo descrito:

7.2 O caso de invalidez de Beneficiário será comprovado mediante inspeção de Saúde por Junta Regular de Saúde, atendendo a requerimento do Servidor Instituidor ou da pessoa responsável, observado o limite de idade disposto no item 5.2, alíneas "a", "c" e "d" desta Instrução, dirigido ao Diretor do Hospital da Aeronáutica jurisdicionado e apresentado na Organização em que estiver lotado ou vinculado, com a finalidade de que aquele Beneficiário venha a adquirir o direito futuro de percepção da pensão, enquanto durar a invalidez.

Portanto, a ferramenta de controle adotada para os riscos pensão civil ilegal a filho inválido, sem comprovação e quanto ao risco de aposentadoria por invalidez (exigência de inspeção de saúde por Junta Regular de Saúde que comprova a invalidez), proporciona segurança na mitigação dos riscos mencionados uma vez que o controle preventivo adotado elimina as falhas inerentes ao processo, identificando-se os possíveis erros e causas de possíveis falhas e atendendo à análise ideal de eficácia, segundo Dias (2008). Por último, quanto ao risco de habilitação ilegal de pensão à concubina, o representante da DIRAP CIVIL entrevistado confirmou que: "Nestes casos, são exigidos três tipos de comprovantes da união estável ou apresentação de ordem judicial que reconheça a união estável (Representante da DIRAPCIVIL)".

A ferramenta de controle adotada para o risco de habilitação ilegal de pensão à concubina (exigência de três tipos de comprovantes da união estável ou apresentação de ordem judicial que reconheça a união estável), proporciona segurança na mitigação do risco mencionado uma vez que elimina as falhas inerentes ao processo, identificando-se os possíveis erros e causas de possíveis falhas e atendendo à análise ideal de eficácia, segundo Dias (2008). O quadro 4 retrata o resumo do estudo da eficácia do processo de pagamento de pessoal civil de acordo com os parâmetros utilizados neste trabalho. 
Quadro 4 - Estudo da Eficácia do Processo de Pagamento de Pessoal Civil

\begin{tabular}{|c|c|c|}
\hline MOTIVO RESUMIDO & Medida de controle adotada pelo COMAER & $\begin{array}{c}\text { Análise da } \\
\text { Eficácia }\end{array}$ \\
\hline $\begin{array}{l}\text { Não pagamento proporcional das } \\
\text { gratificações da pensão civil }\end{array}$ & $\begin{array}{l}\text { Conferência do processo pela OM, DIRAP, SDIP e } \\
\text { CENCIAR ministrada instrução anual da dirap aos } \\
\text { gestores de pagamento de pessoal civil }\end{array}$ & Eficaz \\
\hline $\begin{array}{l}\text { Desvio de recursos de pensionistas } \\
\text { falecidos, transferidos por meio de } \\
\text { adiantamento não resgatado }\end{array}$ & $\begin{array}{l}\text { Atualmente o siape não permite adiantamento a } \\
\text { pessoal civil, conferência da prestação de contas } \\
\text { mensal de folha extraordinária pela sdpp e } \\
\text { cruzamento de dados de óbito do SISOBI com o } \\
\text { SIAPE/SIGEPE }\end{array}$ & Eficaz \\
\hline Pensão civil ilegal a menor sob guarda & $\begin{array}{l}\text { Habilitação de menor sob guarda não é mais } \\
\text { permitida a partir da Lei n }{ }^{\circ} 13.135 / 2015\end{array}$ & Eficaz \\
\hline $\begin{array}{l}\text { Inobservância da paridade dos } \\
\text { benefícios na pensão civil com a } \\
\text { remuneração do cargo efetivo do } \\
\text { falecido. }\end{array}$ & $\begin{array}{l}\text { Instrução anual da DIRAP aos gestores de } \\
\text { pagamento de pessoal civil }\end{array}$ & Eficaz \\
\hline Reajustes pagos indevidamente & $\begin{array}{l}\text { Instrução anual da DIRAP aos gestores de } \\
\text { pagamento de pessoal civil }\end{array}$ & Eficaz \\
\hline Averbação ilegal de tempo de serviço & $\begin{array}{l}\text { Diligências da DIRAP junto aos órgãos } \\
\text { declarantes ou ao INSS quando iniciativa privada }\end{array}$ & Eficaz \\
\hline $\begin{array}{l}\text { Pensão civil ilegal a filho maior } \\
\text { ocupante de cargo público }\end{array}$ & Trilhas de auditoria do TCU & Eficaz \\
\hline $\begin{array}{l}\text { Acúmulo ilegal de proventos/pensões } \\
\text { ou cargos públicos }\end{array}$ & Trilhas de auditoria do TCU & Eficaz \\
\hline Pensão civil ilegal à pessoa designada & $\begin{array}{l}\text { Habilitação de pessoa designada não é mais } \\
\text { permitida a partir da Lei } n^{\circ} 13.135 / 2015\end{array}$ & Eficaz \\
\hline $\begin{array}{l}\text { Pagamento de } \\
\text { gratificação/vantagem/adicional } \\
\text { indevido }\end{array}$ & $\begin{array}{l}\text { Instrução anual da DIRAP aos gestores de } \\
\text { pagamento de pessoal civil }\end{array}$ & Eficaz \\
\hline $\begin{array}{l}\text { Pensão civil ilegal a filho inválido, } \\
\text { sem comprovação }\end{array}$ & $\begin{array}{l}\text { A DIRAP exige laudo atualizado quando } \\
\text { necessário }\end{array}$ & Eficaz \\
\hline $\begin{array}{l}\text { Não aplicação do redutor de pensão } \\
\text { civil prevista no inciso i do art. } 2^{\circ} \text { da } \\
\text { lei } 10.887 / 2004 \text { e ec } 41 / 2003\end{array}$ & $\begin{array}{l}\text { Instrução anual da dirap aos gestores de } \\
\text { pagamento de pessoal civil }\end{array}$ & Eficaz \\
\hline $\begin{array}{l}\text { Aposentadoria por invalidez, sem } \\
\text { comprovação }\end{array}$ & $\begin{array}{l}\text { A DIRAP exige inspeção de saúde por junta } \\
\text { regular de saúde que comprove a invalidez }\end{array}$ & Eficaz \\
\hline $\begin{array}{l}\text { Habilitação ilegal de pensão à } \\
\text { concubina }\end{array}$ & $\begin{array}{l}\text { A DIRAP exige três comprovantes da união estável } \\
\text { ou ordem judicial }\end{array}$ & Eficaz \\
\hline
\end{tabular}

Fonte: Elaboração própria (2016)

Após análise de cada risco encontrado nos acórdãos do TCU acerca de pagamento de pessoal civil, no período de 2006 a 2015, constata-se que todos os erros e fraudes possuem atualmente medidas de controle para mitigá-los. Com isso, a instituição demonstrou ser eficaz também no cumprimento do objetivo de executar e controlar o pagamento de pessoal civil com excelência por meio do aprimoramento contínuo do processo de pagamento de pessoal civil e da constante preocupação com a mitigação do risco. Mais uma vez, reforça-se que cabe aos gestores envolvidos no processo de pagamento de pessoal civil adotarem postura de comprometimento com a ética na execução do seu trabalho e com o profissionalismo, tomando conhecimento da legislação aplicável ao assunto, atuando em conformidade com as normas e buscando atualização contínua. 


\section{CONSIDERAÇÕES FINAIS}

Esse artigo objetivou checar a eficácia das medidas de controle adotadas pelo Comando da Aeronáutica produtpara a mitigação de riscos de dano ao Erário no processo de pagamento de pessoal civil. A partir do modelo conceitual desenhado e suportado pelo percurso metodológico, foi possível avaliar que o processo de pagamento de pessoal do Comando da Aeronáutica é eficaz na medida em que tem sido adotadas medidas de controle que possibilitam a detecção dos riscos encontrados nos acórdãos do TCU no período investigado. Em tempo, o paper não trouxe contribuição teórica, mas reflexões sobre como aplicação de ferrmanda de gestão na busca por eficácia na esfera governamental.

Cabe ressaltar, a priori, que o processo de pagamento de pessoal segue os procedimentos delineados nos manuais e instruções do Comando da Aeronáutica, com exceção da ICA 47-2/2005 de habilitação à pensão militar e da ICA 47-3/2003 de habilitação à pensão civil. No entanto, ambas instruções estão desatualizadas com relação ao manual MCA 177-2 e à edição da Lei n ${ }^{\circ}$ 8.112, de 11 de dezembro de 1990, por meio da Lei $\mathrm{n}^{\circ} 13.135$, de 17 de junho de 2015 a qual revogou a possibilidade de pessoa designada e de menor sob guarda requererem o benefício de habilitação à pensão civil.

Por meio da pesquisa relizada foi possível realizar a análise de riscos e a avaliação da eficácia o processo de pagamento de pessoal do Comando da Aeronáutica. Quanto à análise de riscos verificou-se que os riscos de pagamento de pessoal civil detectados foram enquadrados em níveis de médio impacto e de media a alta probabilidade, não tendo sido identificados riscos caracterizados como de baixa probabilidade e impacto. A matriz de riscos gerada permite recomendar uma priorização quanto à adoção de medidas que venham a mitigar os riscos identificados.

Recomenda-se que COMAR priorize a mitigação principalmente dos riscos enquadrados nos maiores patamares, quais sejam: não pagamento proporcional das gratificações da pensão civil, desvio de recursos de militares/pensionistas falecidos, licenciados ou transferidos, pensão civil ilegal a menor sob guarda, inobservância da paridade dos benefícios na pensão civil com a remuneração do cargo efetivo do falecido, reajustes pagos indevidamente, averbação ilegal de tempo de serviço, pensão civil ilegal a filho maior ocupante de cargo público e acúmulo ilegal de proventos/pensões ou cargos públicos. E em seguida, priorize a mitigação dos riscos de patamares médios, quais sejam: pensão civil à pessoa designada, pagamento de gratificação/vantagem adicional indevido, pensão civil ilegal a filho inválido, sem comprovação, não aplicação do redutor de pensão civil com previsão legal, aposentadoria por invalidez, sem comprovação e habilitação ilegal de pensão à concubina.

No que se refere à avaliação da eficácia do processo de pagamento de pessoal civilrealliado pelo COMAER, constatou-se sua eficácia por meio da busca constante pelo cumprimento do objetivo de executar e controlar o pagamento de pessoal por meio do aprimoramento contínuo da legislação aplicada a pagamento de pessoal civil e pela constante preocupação com a mitigação do risco. Como possibilidade de melhoria do processo de pagamento de pessoal civil, sugerem-se: atualização da ICA 47-3/2003 de habilitação à pensão civil, incluir automatização do cruzamento dos óbitos entre o SISOBI e SIGEPE mensalmente, enquanto o SIGEPE não cruza automaticamente os óbitos lançados no SISOBI, o processo de cotejamento poderia incluir este procedimento como rotina mensal.

Por fim, registra-se que as dificuldades encontradas pelos representantes entrevistados consistem principalmente na falta de pessoal para atender à demanda de conferência dos processos de pagamento de pessoal, na indisponibilidade de acesso ao SIGEPE mensalmente por alguns dias o que prejudica o andamento dos serviços dos gestores e na restrição orçamentária para realização de cursos, pagamento de diárias e passagens o que prejudica a profissionalização e atualização acerca da legislação vigente. A intensificação e constância de processos de treinamentos e atualização de conhecimentos dos responsáveis 
pelo processo de pagamento de pessoal no Comando da Aeronáutica aumentará a probabilidade de evitar erros na montagem ou análise da legalidade dos processos que geram demora na análise, bem como sobrecarga dos Órgãos Centrais (SDPP, DIRAP, SDIP e CENCIAR) para conferência dos processos analisados.

\section{REFERÊNCIAS}

AVALOS, J. M.A.. Auditoria e gestão de riscos. Instituto Chiavenato (org.). São Paulo: Saraiva, 2009.

BARDIN, L. (2006). Análise de conteúdo (L. de A. Rego \& A. Pinheiro, Trads.). Lisboa: Edições 70. (Obra original publicada em 1977)

BERTOLUCCI, R. G. Estudo sobre o gerenciamento de risco corporativo: proposta de um modelo. Dissertação de Mestrado. Universidade Metodista de Piracicaba, 2005.

BRAGA, M.. Lógica de riscos nas atividades de auditoria governamental: um promotor da qualidade na gestão pública? Revista TCE-PE Recife v. 20 n. 20 p. 130-142 dez. 2013.

BRASIL. Comando da Aeronáutica. História. Disponível em: https://www.dirint.aer.mil.br/index.php?option=com_content\&view=article\&id=2\&Itemid=119. Acesso em: 30 mar. 2016.

BRASIL. Comando da Aeronáutica. RCA n 12-1 de 29 de dezembro de 2014 (RADA). Regulamento de Administração da Aeronáutica. [Brasília]. Dez, 2014.

BRASIL. Constituição da República Federativa do Brasil de 1988. Brasília, 1988. Disponível em:< http://www.planalto.gov.br/ccivil_03/constituicao/ConstituicaoCompilado.htm>. Acesso em: 30 abr. 2016.

BRASIL. Tribunal de Contas da União. Instrução Normativa n. ${ }^{0} 01$, de 06 de abril de 2001. Define diretrizes, princípios, conceitos e aprova normas técnicas para a atuação do Sistema de Controle Interno do Poder Executivo Federal. Disponível em:

<http://www.cgu.gov.br/Legislacao/Arquivos/InstrucoesNormativas/IN01_06abr2001.pdf >. Acesso em: 28 ago. 2014.

BRASIL. Tribunal de Contas da União. Roteiro de Aplicação da Metodologia de Análise de Risco para Escolha de Temas de Fiscalização. Brasília, 2003. Documento não publicado (uso interno do TCU).

BRASIL. Tribunal de Contas da União. Instrução Normativa no 47/TCU/2004, de 27 de outubro de 2004. Estabelece normas de organização e apresentação de Processos de tomada e prestação de contas. Brasília-DF: Imprensa Nacional, 2004.

BRASIL. Tribunal de Contas da União. Instrução Normativa n 57/2008.Estabelece normas de organização e apresentação dos relatórios de gestão e dos processos de contas da administração pública federal.Brasília, 2008. Disponível em:https://contas.tcu.gov.br/juris/Web/Juris/ConsultarAtoNormativo/ConsultarAtoNormativo.faces. Acesso em: 30 abr. 2016.

BRASIL. Tribunal de Contas da União. Instrução Normativa TCU n. ${ }^{\mathbf{7} 71 / 2012}$. Disponível em: $<$ http:// www.tcu.gov.br/Consultas/Juris/Docs/judoc/IN/20121204/INT2012-071.rtf>. Acesso em: 28 ago. 2014. 
BRASIL. Tribunal de Contas da União. Manual de Tomada de Contas Especial. Disponível em: $<$ http://www.cgu.gov.br/assuntos/auditoria-e-fiscalizacao/avaliacao-da-gestao-dosadministradores/tomadas-de-contas-especiais/arquivos/manualtce.pdf >. Acesso em: 14 mar. 2016.

BRITO, O.S.de. Controladoria de risco-retorno em instituições financeiras. São Paulo: Saraiva, 2003.

CAMERON, K.S.; WHETTEN, D.A. (Eds.).. Organizational effectiveness. A comparison of multiple models. New York: Academic Press, 1983.

CARVALHO, C. M. S. Organizações, atores envolvidos e partes interessadas: determinantes da saliência dos stakeholders e sua relação com o desempenho organizacional. Tese de Doutoramento, Faculdade de Psicologia e de Ciências da Educação, Universidade de Coimbra, Portugal,2007.

FAERMAN, S.R.; QUINN, R.E. Effectiveness: the perspective from organization theory. In: The Review of Higher Education, 9, pp. 83-100,,1985.

FERNANDES, A.J.G. . Impacto do Planeamento Estratégico na Eficácia Organizacional das Instituições Portuguesas de Ensino Superior Agrário. Tese de Doutoramento em Gestão, Universidade Trás-os-Montes e Alto Douro, Vila Real, Portugal, 2006.

FERNANDES, A. J. G; RIBEIRO, M.I. B. Planeamento Estratégico e Eficácia Organizacional no Ensino Superior Agrário. Que relação? Revista de Contabilidade e Gestão 7, 1: 97-116, 2009.

FREITAS, D. M. Percepção do líder acerca da eficácia organizacional: Estudo de caso da federação portuguesa de canoagem. Dissertação de Mestrado não publicada, Universidade do Porto, Portugal, 2010.

GIACOMO, W.Á.Di. New public management no Canadá e a gestão pública contemporânea. Interfaces Brasil/Canadá. n. 5, 2005.

GIL, A.C.. Como Elaborar Projetos de Pesquisa.4.ed. São Paulo: Atlas,2009.

GLÓRIA, K.G.. A relação entre o planejamento estratégico e a eficácia organizacional em instituições públicas: $\mathrm{O}$ caso dos Institutos Federais de Educação, Ciência e Tecnologia no Brasil. Tese de Doutoramento em Gestão, Universidade Trás-os-Montes e Alto Douro, Vila Real, Portugal, 2013.

GRATERON, I.R.G.. Auditoria de gestão: utilização de indicadores de gestão no setor público. FEA/USP, São Paulo, 1999.

GONZALEZ, I. V. D. P.et al. Pesquisa de clima organizacional: um estudo em uma secretaria municipal de educação do estado do Espírito Santo.Qualit@s Revista Eletrônica, v. 12, n. 2.2011.

IFAC. International Federation of Accountants. (1999). Disponível em :<http://www.ifac.org>. Acesso em: 04 ago. 2015.

IFAC. International Federation of Accountants. (2001). Disponível em: 〈http://www.ifac.org $>$. Acesso em: 04 ago. 2015.

KEATING, Michael. Public Management Reform and Economic and Social Development. OECD Journal of Budgeting. OECD: 2001.

OLIVEIRA, A.B.S.. Métodos e técnicas de pesquisa em contabilidade. São Paulo: Saraiva, 2003.

PADOVEZE, C.L.; BERTOLUCCI, R.G.. Gerenciamento do risco corporativo em controladoria: enterprise risk management (ERM). 2.ed. São Paulo: Atlas, 2013.

REIS, H.da C.; MACHADO JR. A Lei 4.320 comentada. 25. Ed.Rio de Janeiro:IBAM,1993. 
REGO, A.; CUNHA, M. P. O Tao da Eficácia: manuscrito em preparação. São Paulo: Ática, 2006.

ROBBINS, S. Organization Theory: Structure, Design, and Applications, Prentice Hall, 1990.

SAVOIE, A.; MORIN, E. , Développements Récents dans les Représentations de l'Efficacité Organisationnelle, Psychologica, $n^{\circ} .27,2001$.

STEINBERG, R.M. et al. Enterprise risk management framework (DRAFT). Comittee of Spon-soring Organizations of the tradewa Comission (COSO), 2003. 